manned missions beyond low-Earth orbit. Doug Cooke, NASA's associate administrator for exploration systems, expanded on this during the House subcommittee hearing, saying that NASA officials plan to develop a vehicle with an initial capability of 70-100 tonnes, which would allow the agency to launch it by 2016 or soon after.

Meanwhile, funding remains in limbo. The previous Congress failed to pass a budget for this year, and November's midterm elections swept a Republican majority into the House of Representatives that is bent on making drastic cuts to government spending. With the two parties deadlocked over the 2011 budget, members have had to opt for a series of short-term measures that maintain 2010 programmes and funding levels. Constellation continues to be funded, delaying work on any new initiative.

Some argue that the roughly $\$ 250$ million spent on Constellation in the current fiscal year has not been wasted. For example, on 21 March, Lockheed Martin Space Systems, based in Denver, Colorado, unveiled a new simulation centre where engineers will try out docking manoeuvres with the programme's Orion crew capsule. The capsule meets most requirements from the authorization bill and all indications are that it will be selected as the MPCV, says Larry Price, deputy programme manager for Orion. Continuing Constellation's contracts in this way is in NASA's best interests, he says. "As you can imagine, it would have been hugely inefficient to stop something, redistribute the labour force, and start it over again especially if it's exactly the same," he says.

Even if NASA finally achieves the clarity Obama promised a year ago, it faces many years with no way to send people into space. The last time the agency had a similar gap between the end of the Apollo programme in 1975 and the first shuttle launch in 1981 - it knew what was to come next. The shuttle programme had been announced three years before Apollo's conclusion.

The current situation is much worse, said James Maser, chairman of the corporate membership committee at the American Institute of Aeronautics and Astronautics, during the House subcommittee hearing. "We simply do not know what is next," he said.

BIOMEDICAL RESEARCH

\title{
Rare-disease project has global ambitions
}

\section{Consortium aims for hundreds of new therapies by 2020 .}

\section{BY ALISON ABBOTT}

$\mathrm{P}$ rader-Willi syndrome. Fabry renal disease. Spinocerebellar ataxia. Few people have heard of these and the other 'rare diseases', some of which affect only hundreds of patients worldwide. Drug companies searching for the next blockbuster pay them little attention. But the diseases are usually incurable - and there are thousands of them.

This week, the US National Institutes of Health (NIH) and the European Commission launch a joint assault on these conditions, whose small numbers of patients make it difficult to test new treatments and develop diagnostic methods. The International Rare Disease Research Consortium being formed under the auspices of the two bodies has the ambitious goal of developing a diagnostic tool for every known rare disease by 2020 , along with new therapies to treat 200 of them. "The number of individuals with a particular rare disease is so small that we need to be able to pool information from patients in as many countries as possible," says Ruxandra Draghia-Akli, the commission's director of health research.

At the launch meeting in Bethesda, Maryland, on 6-8 April, prospective partners will map out research strategies to identify diagnostic biomarkers, design clinical trials and coordinate genome sequencing in these diseases. Nearly all the rare diseases, of which there are an estimated 6,000-8,000, are the result of small genetic changes.

The meeting will also discuss the governance of the project, which is most likely to be modelled on the pioneering Human Genome Project. As such, the consortium is open to research agencies and organizations from all over the world. Representatives from countries including Canada, Japan and some individual European nations are all attending the

meeting, and may join the consortium. Those wishing to participate will have to pledge a minimum financial contribution, which has not yet been agreed, and share all relevant data. Indeed, the project will have to overcome numerous obstacles to information sharing, such as the fact that physicians in different countries often use entirely different words to describe the same disease.

Draghia-Akli points out that the project could yield major benefits for the emerging field of personalized medicine - another political priority for the NIH and the commission - which also faces the challenge of

"We need to be able to pool information from patients in as many countries as possible." and controlled clinical trials when deciding whether to approve new medicines, and one of the aims of the consortium will be to develop alternative clinical-trial methods for diseases that affect few people.

These methods are becoming ever more important now that genome analysis is helping to break down common diseases into ever smaller subclasses. "Soon there will be no disease called breast cancer," says Draghia-Akli. Instead, the catch-all term will be replaced by "a large number of rare diseases, each of which causes malignant growth in breast tissue and requires individual treatment", she says.

The commission will launch a $€ 100$-million (US\$140-million) call for research proposals in July, which will support the consortium's scientific goals by focusing heavily on developing appropriate clinical trials.
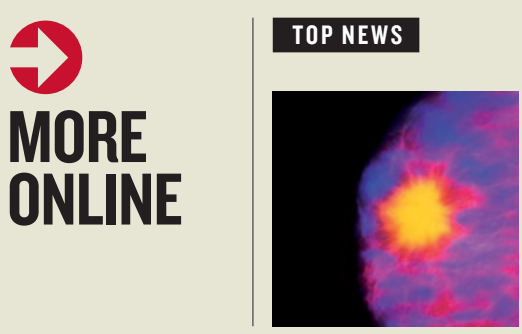

Fifty genome sequences reveal breast cancer's complexity go.nature. com/7jfuji

\section{MORE NEWS}

- Carbon-rich mangrove forests are ripe for conservation go nature. com/1djphk

- The amazing disappearing antineutrino go.nature.com/cvm8xi - China vows to clean up rural environment go.nature.com/extggt

\section{FUKUSHIMA EXPERT ANALYSIS}

Andrew Sherry: The technology that makes modern nuclear reactors safer than Fukushima go.nature.com/9ghk9c

David Brenner: Why we still don't understand the risks of low doses of radiation go.nature.com/67ygor 